\section{BRAZIULIAN JOURNAL \\ OF MEDICAL AND BIOLOGICAL RESHARCH}

www.bjournal.com.br
ISSN 0100-879X

Volume 42 (10) 870-992 October 2009

BIOMEDICAL SCIENCES

AND

CLINICAL INVESTIGATION

Braz J Med Biol Res, October 2009, Volume 42(10) 949-953

Effect of frequency of static stretching on flexibility, hamstring tightness and electromyographic activity

A.P. Marques, A.A.P. Vasconcelos, C.M.N. Cabral and I.C.N. Sacco

The Brazilian Journal of Medical and Biological Research is partially financed by
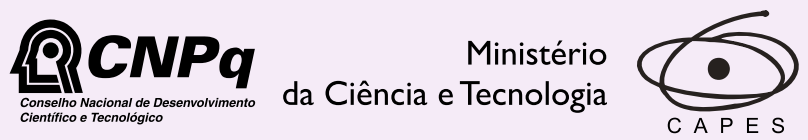

Ministério da Educação
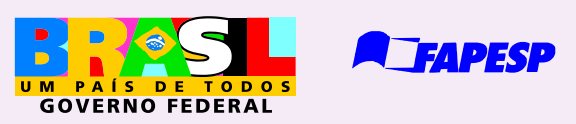

Institutional Sponsors 


\title{
Effect of frequency of static stretching on flexibility, hamstring tightness and electromyographic activity
}

\author{
A.P. Marques ${ }^{1}$, A.A.P. Vasconcelos ${ }^{1}$, C.M.N. Cabral ${ }^{2}$ \\ and I.C.N. Sacco ${ }^{1}$ \\ 1Departamento de Fisioterapia, Fonoaudiologia e Terapia Ocupacional, Faculdade de Medicina, \\ Universidade de São Paulo, São Paulo, SP, Brasil \\ ${ }^{2}$ Programa de Mestrado em Fisioterapia, Departamento de Fisioterapia, \\ Universidade Cidade de São Paulo, São Paulo, SP, Brasil
}

\begin{abstract}
We compared the effect of the number of weekly repetitions of a static stretching program on the flexibility, hamstring tightness and electromyographic activity of the hamstring and of the triceps surae muscles. Thirty-one healthy subjects with hamstring tightness, defined as the inability to perform total knee extension, and shortened triceps surae, defined by a tibiotarsal angle wider than $90^{\circ}$ during trunk flexion, were divided into three groups: G1 performed the stretching exercises once a week; G2, three times a week, and G3, five times a week. The parameters were determined before and after the stretching program. Flexibility improved in all groups after intervention, from $7.65 \pm 10.38$ to $3.67 \pm 12.08$ in G1, from $10.73 \pm 12.07$ to $0.77 \pm 10.45$ in $\mathrm{G} 2$, and from $14.20 \pm 10.75$ to $6.85 \pm 12.19 \mathrm{~cm}$ in $\mathrm{G} 3$ ( $P<0.05$ for all comparisons). The increase in flexibility was higher in $\mathrm{G} 2$ than in $\mathrm{G} 1(\mathrm{P}=0.018)$, while $\mathrm{G} 2$ and $\mathrm{G} 3$ showed no significant difference $(\mathrm{G} 1: 4 \pm 2.17, \mathrm{G} 2: 10 \pm 5.27 ; \mathrm{G} 3: 7.5 \pm 4.77 \mathrm{~cm})$. Hamstring tightness improved in all groups, from $37.90 \pm 6.44$ to $29 \pm 11.65$ in G1, from $39.82 \pm 9.63$ to $21.91 \pm 8.40$ in $\mathrm{G} 2$, and from $37.20 \pm 6.63$ to $26.10 \pm 5.72^{\circ}$ in $\mathrm{G} 3$ ( $P<0.05$ for all comparisons). During stretching, a statistically significant difference was observed in electromyographic activity of biceps femoris muscle between $G 1$ and $G 3(P=0.048)$ and $G 2$ and $G 3(P=0.0009)$. No significant differences were found in electromyographic activity during maximal isometric contraction. Stretching exercises performed three times a week were sufficient to improve flexibility and range of motion compared to subjects exercising once a week, with results similar to those of subjects who exercised five times a week.
\end{abstract}

Key words: Electromyography; Flexibility; Muscle stretching exercises; Range of motion

\section{Introduction}

The frequency and duration of muscle stretching may interfere with the improvement of flexibility. Seeking to optimize these variables, several authors have investigated the effect of duration of stretching and the number of daily repetitions on flexibility (1-3), suggesting that 30 -s duration of stretching one or three times a day is effective for increasing muscle flexibility. However, studies assessing the number of weekly static stretching repetitions on the flexibility of hamstring and triceps surae muscles are scarce.

Electromyography (EMG) is not often used during and/ or immediately after stretching in order to obtain information about therapeutic efficacy. In contrast to current theories, stretching techniques yield gains in range of motion
(ROM) without necessarily reducing the EMG activity of the stretched muscles, as observed by Ferber et al. (4), who analyzed the effect of stretching exercises on ROM of knee extension and EMG activity of the biceps femoris and lateral gastrocnemius.

Studies have also assessed EMG activity during maximal isometric contraction (MIC) after a period of stretching exercises. Cabral et al. (5) did not find changes in EMG activity after an eight-week stretching treatment of patellofemoral patients. Similarly, McBride et al. (6) did not observe significant differences in EMG activity after one session of static stretching.

The objective of the present study was to assess the

Correspondence: A.P. Marques, Departamento de Fisioterapia, Fonoaudiologia e Terapia Ocupacional, USP, Rua Cipotânea, 51, 05360-160 São Paulo, SP, Brasil. E-mail: pasqual@usp.br

Research supported by FAPESP (\#2002/04609-5 and \#2003/03713-6).

Received December 6, 2008. Accepted August 12, 2009. Available online September 28, 2009. 
effect of the number of weekly repetitions of static stretching on leg flexibility and hamstring tightness. EMG activity of hamstring and triceps surae muscles during stretching and MIC in individuals submitted to different stretching programs was also obtained and compared. Our hypothesis was that different weekly frequencies of muscular stretching would not change flexibility, ROM or EMG activity during MIC stretching.

\section{Material and Methods}

We studied 31 healthy volunteers. Inclusion criteria were shortened hamstring muscles, defined by an incomplete knee extension in the active-knee-extension test (7), when the subject failed to straighten the knee to its full extension $\left(0^{\circ}\right)$ by $25^{\circ}$ or more; and shortened triceps surae, defined as a tibiotarsal angle wider than $90^{\circ}$ during trunk flexion (8). Individuals with lower limb pain or injuries were excluded. Regardless of the level of baseline physical activity, participants were asked not to change the frequency and/or intensity of physical activity.

Participants were separated into three groups, defined as a function of the stretching program: $\mathrm{G} 1(\mathrm{~N}=10,23 \pm 4$ years) did the proposed stretching exercises once a week; G2 ( $N=11,22 \pm 4$ years) exercised three times a week, and $\mathrm{G} 3(\mathrm{~N}=10,22 \pm 3$ years) exercised five times a week. Subjects were allocated according to order of evaluation: the first subject was allocated to $\mathrm{G} 1$, the second to $\mathrm{G} 2$, and so on. Most subjects were women, $60 \%$ in $\mathrm{G} 1$ and $\mathrm{G} 3$, and $90.9 \%$ in G2. Physical activities were routinely performed by $50 \%$ of $\mathrm{G} 1$ subjects, by $45.5 \%$ of $\mathrm{G} 2$ subjects, and by $60 \%$ of $\mathrm{G} 3$ subjects.

The required sample size was calculated using an $80 \%$ statistical power to detect a $30 \%$ difference in the intervention groups. $\mathrm{N} \leq 5 \%$ and a confidence interval of $95 \%$ were considered to be significant.

The study was approved by the Ethics Committee for analysis of research projects of the University Hospital of the University of São Paulo Medical School - protocol \#954/01) and written informed consent was obtained from all volunteers.

Global flexibility was assessed by the fingertip-to-floor test, which evaluates the flexibility of the posterior chain muscles. Each subject was instructed to try to touch the floor with the fingertip with knees straight. The vertical distance between the third fingertip and the floor was measured. Reaching beyond the horizontal standing surface was recorded as a negative value (9).

Hamstring tightness of the right knee was measured using the active-knee-extension test (7). Complete knee extension was $0^{\circ}$ and the lack of knee extension was measured with a goniometer and considered to indicate hamstring tightness, an isolated measure of knee flexibility. For both variables, values near zero show good flexibility and complete knee extension, indicating the absence of hamstring tightness.

EMG evaluation was conducted using an 8-channel EMG instrument with an analogical-digital 12-bit resolution converter CAD 12/32 and active surface electrodes (EMG System do Brasil, Brazil). Data were collected using the AqDados 5.0 software (Lynx, Brazil) with 1000-Hz frequency per channel. The skin was shaved and cleaned with alcohol. A reference electrode was attached to each subject's ipsilateral wrist. Pairs of electrodes were placed on the subjects' right lower limb at a distance of approximately $2 \mathrm{~cm}$ between centers, over the motor point of the semitendinous, biceps femoris, and medial and lateral gastrocnemius muscles. Motor points were chosen to assure reliability of the tests, as well as to assure reproducibility (10) and were determined using a pulse generator (model Nemesys, Quark, Brazil).

The EMG activity of the semitendinous and biceps femoris muscles was measured during three repetitions of static stretching of the hamstring. EMG activity of the gastrocnemius muscles was measured during three repetitions of the triceps surae muscle stretching. The measurement was made over a period of $6 \mathrm{~s}$ at a sampling rate of $1000 \mathrm{~Hz}$, starting after a 24-s stretch.

EMG signals (6s) were also acquired during hamstring MIC, obtained with the subject in the prone position with knee flexion of approximately $90^{\circ}$, by vigorous verbal encouragement of knee flexion while manual resistance was applied against flexion force. We repeated the procedure for the triceps surae muscles, now with resistance being applied to the plantar surface (5). EMG muscle evaluations were performed in random order.

The stretching program lasted 4 weeks. All subjects performed the stretching exercises under the supervision of the physical therapist once a week, to encourage stretching and to correct occasional compensations that might occur during the exercises. Thus, G1 subjects performed all stretching exercises in the presence of the therapist. Subjects in G2 and G3 exercised with the physical therapist once a week and repeated the exercises at home as scheduled. They were carefully instructed about the exercises, having received a booklet with information on the study and illustrated guidance written in lay language. We also included in the booklet a calendar for subjects to record the days of the exercises. The forms were checked weekly and participants not strictly following the stretching program were excluded from the study. We report here only on those who followed the program according to the instructions ( $\mathrm{G} 1: \mathrm{N}=10 ; \mathrm{G} 2: \mathrm{N}=11 ; \mathrm{G} 3: \mathrm{N}=10$ ).

Two stretching positions were proposed for the hamstrings and triceps surae muscles. Hamstring muscles were stretched with hip in flexion and knee in extension with the subject in the orthostatic and supine positions. Triceps surae muscles were stretched with hip and knee extension and plantar dorsiflexion, with the subject in the orthostatic position. Stretching was to be maintained for $30 \mathrm{~s}$, both lower limbs were stretched and each exercise was performed twice.

EMG signals were processed using the routines of the Origin 6.0 software. Root mean square values, in $\mu \mathrm{V}$, were calculated. These values "represent the signal power and thus 
have a clear physical meaning" (11). In order to improve data reliability, the first and last seconds of the signal were discarded, and only the intermediate $4 \mathrm{~s}$ were analyzed.

All variables were analyzed for normality using the Shapiro-Wilk test. When data distribution was normal, groups were compared by one-way analysis of variance (ANOVA) followed by the Scheffé post hoc test. Pre- and post-data were analyzed by the paired $t$-test. For non-parametric data, we used the Kruskal-Wallis test followed by the Mann-Whitney post hoc U-test to compare variables between groups, and the Wilcoxon test for pre- and post-program data. The level of significance was set at $\alpha=0.05$ in all analyses.

\section{Results}

All groups presented similar flexibility and hamstring tightness before the program $(P>$ 0.05 for all comparisons) and flexibility was improved in all groups after the program $(P<$ 0.05). For flexibility gain (difference between post- and pre-values), G2 showed a significantly greater gain than $\mathrm{G} 1(P=0.018)$, but no difference was found between $\mathrm{G} 2$ and $\mathrm{G} 3$. For mean hamstring tightness, significant differences were observed in the three groups after intervention $(P<0.05)$. ROM gain (expressed as the difference in hamstring tightness between post- and pre-values) was not significantly different between groups $(P$ $=0.069$; Table 1).

Only the lateral gastrocnemius muscle showed a statistically significant increase of EMG activity in $\mathrm{G} 1(\mathrm{P}=0.026)$. For $\mathrm{G} 2$, no significant differences were detected between the values obtained before and after the stretching program for any of the measured muscles. In G3, we found a significant reduction of EMG activity during biceps femoris stretching $(P=0.024)$.

We also found significant differences in the EMG activity of the biceps femoris muscle after the stretching program between $\mathrm{G} 1$ and $\mathrm{G} 3(\mathrm{P}=0.048)$ and $\mathrm{G} 2$ and $\mathrm{G} 3(\mathrm{P}=0.0009)$. The data suggest a more significant reduction in the EMG activity of this muscle in G3 subjects at the end of the program.

Regarding the EMG data obtained during MIC, no significant differences between preand post-stretching values were detected in any of the groups (Table 2).
Table 1. Flexibility and hamstring tightness, expressed as range of motion (ROM), before (pre) and after (post) a stretching program.

\begin{tabular}{lccc}
\hline & Group 1 $(\mathrm{N}=10)$ & Group 2 (N=11) & Group 3 (N=10) \\
\hline Flexibility - pre (cm) & $7.65 \pm 10.38^{1}$ & $10.73 \pm 12.07^{2}$ & $14.20 \pm 10.75^{3}$ \\
Flexibility - post (cm) & $3.67 \pm 12.08^{1}$ & $0.77 \pm 10.45^{2}$ & $6.85 \pm 12.19^{3}$ \\
Flexibility gain (cm) & $4 \pm 2.17^{4}$ & $10 \pm 5.27^{4}$ & $7.5 \pm 4.77$ \\
ROM - pre (degrees) & $37.90 \pm 6.44^{5}$ & $39.82 \pm 9.63^{6}$ & $37.20 \pm 6.63^{7}$ \\
ROM - post (degrees) & $29.00 \pm 11.65^{5}$ & $21.91 \pm 8.40^{6}$ & $26.10 \pm 5.72^{7}$ \\
ROM gain (degrees) & $8.5 \pm 10.12$ & $19 \pm 12.85$ & $11 \pm 4.77$ \\
\hline
\end{tabular}

Data are reported as means $\pm \mathrm{SD} .{ }^{1,2,3} \mathrm{P}<0.05$ after the stretching program for groups 1,2 , and 3 , respectively (Wilcoxon test). ${ }^{4} \mathrm{P}<0.018$ between groups 1 and 2. $5,6,7 \mathrm{P}<0.05$ after the stretching program for groups 1,2 and 3 , respectively (paired $t$-test).

Table 2. Electromyographic activity (root mean squares in $\mu \mathrm{V}$ ) during muscle stretching and maximum isometric contraction.

\begin{tabular}{|c|c|c|c|}
\hline & Group 1 & Group 2 & Group 3 \\
\hline \multicolumn{4}{|l|}{ Stretching } \\
\hline \multicolumn{4}{|c|}{ Semitendinous } \\
\hline Pre & $4.6 \pm 2.6$ & $5.5 \pm 2.4$ & $5.5 \pm 1.6$ \\
\hline Post & $5.5 \pm 3.9$ & $6.2 \pm 2.6$ & $5.7 \pm 4.9$ \\
\hline \multicolumn{4}{|c|}{ Biceps femoris } \\
\hline Pre & $6.4 \pm 4.1$ & $6.3 \pm 4.1$ & $7.1 \pm 3.9^{4}$ \\
\hline Post & $8.5 \pm 6.4^{1}$ & $5.7 \pm 3.4^{3}$ & $3.3 \pm 1.1^{1,3,4}$ \\
\hline \multicolumn{4}{|c|}{ Medial gastrocnemius } \\
\hline Pre & $5.6 \pm 2.9$ & $8.4 \pm 4.6$ & $10.2 \pm 7.1$ \\
\hline Post & $8.6 \pm 6.1$ & $7.6 \pm 2.6$ & $6.5 \pm 2.6$ \\
\hline \multicolumn{4}{|c|}{ Lateral gastrocnemius } \\
\hline Pre & $8.7 \pm 4.3^{2}$ & $15.5 \pm 7.4$ & $14.9 \pm 9.3$ \\
\hline Post & $12.8 \pm 6.3^{2}$ & $14.9 \pm 7.3$ & $10.9 \pm 4.9$ \\
\hline \multicolumn{4}{|c|}{ Maximum isometric contraction } \\
\hline \multicolumn{4}{|c|}{ Semitendinous } \\
\hline Pre & $92.0 \pm 61.5$ & $99.6 \pm 42.5$ & $83.6 \pm 53.2$ \\
\hline Post & $98.3 \pm 32.3$ & $129.2 \pm 72.3$ & $111.2 \pm 67.3$ \\
\hline \multicolumn{4}{|c|}{ Biceps femoris } \\
\hline Pre & $77.7 \pm 50$ & $84.3 \pm 46.1$ & $77.8 \pm 54.7$ \\
\hline Post & $100.2 \pm 20.4$ & $112.2 \pm 53.9$ & $108.4 \pm 106$ \\
\hline \multicolumn{4}{|c|}{ Medial gastrocnemius } \\
\hline Pre & $39.8 \pm 23.5$ & $49.9 \pm 27.1$ & $47.4 \pm 22.3$ \\
\hline Post & $53.0 \pm 40.7$ & $65.2 \pm 24.8$ & $57.7 \pm 23.0$ \\
\hline \multicolumn{4}{|c|}{ Lateral gastrocnemius } \\
\hline Pre & $92.5 \pm 60.3$ & $109.6 \pm 56.4$ & $68.2 \pm 50.2$ \\
\hline Post & $101.2 \pm 85.5$ & $107.0 \pm 54$ & $107.1 \pm 44.6$ \\
\hline
\end{tabular}

Data are reported as means $\pm \mathrm{SD} .{ }^{1} \mathrm{P}=0.048$ compared to group 3 (Scheffé test). ${ }^{2} \mathrm{P}=0.026$ for the comparison between pre- and post-program values for group 1 (paired $t$-test). ${ }^{3} \mathrm{P}=0.0009$ compared to group 3 values (Scheffé test). ${ }_{4} \mathrm{P}=0.024$ for the comparison between pre- and post-program values for group 3 (paired $t$-test). 


\section{Discussion}

Several studies have reported increased flexibility and ROM after stretching programs $(1,12,13)$ and the present results support these findings. All groups improved muscle flexibility and hamstring tightness after the stretching program. Regarding flexibility gains, although there was no significant difference between G2 and G3, G2 presented the highest gain in flexibility when compared to the other two. This observation is clinically relevant, suggesting that stretching three times a week is sufficient to improve flexibility compared to stretching at a higher frequency. Accordingly, treatment time could be optimized.

It is well known that gains in flexibility involve biomechanical, neurological and molecular mechanisms that determine myofibrillogenesis as a long-term result (1416). The gains in flexibility can also be associated with increased tolerance to pain and increased viscous elastic properties of the muscle-tendon units (17). In muscle strengthening, when sarcomeres are added in parallel to the muscle fibers, a resting period of 36 to $48 \mathrm{~h}$ is recommended between exercise sessions. If flexibility training generates protein synthesis similar to that induced by hypertrophy training, then intervals of 36 to $48 \mathrm{~h}$ should be scheduled between sessions in order to prevent excessive catabolism (18).

EMG is often recognized as an important instrument to analyze muscle response to specific tasks or therapy programs (11). The assessed muscles represent the posterior chain of muscles and EMG changes after the stretching program may reflect global flexibility and knee ROM.

Regarding data acquired during stretching, despite the absence of statistical significance, it is important to focus on the clinical relevance of the results. G1 showed a trend to an increase in EMG activity after the stretching program, with a statistically significant difference for the lateral gastrocnemius muscle. In contrast, G2 and G3 showed a significant decrease for the biceps femoris muscle in $\mathrm{G} 3$, which may be linked to the flexibility gain in the hamstring and triceps surae muscles, since the gain was greater than in G1. Increased flexibility caused by the viscoelastic properties of the muscles (14) may have led to a reduced muscle spindle response, with a consequent reduction of the EMG signal.

If this hypothesis is correct, then it follows that the number of static stretching repetitions should interfere with the EMG measured during stretching. Although G1 also gained some flexibility, this was probably not sufficient to reduce EMG activity. G3 showed a stronger trend to a reduced EMG activity after the program when compared to $\mathrm{G} 1$ and $\mathrm{G} 2$, particularly in the biceps femoris muscle. Thus, a larger number of repetitions may lead to a more pronounced reduction in EMG activity.
Another hypothesis to explain the reduced EMG activity in $\mathrm{G} 2$ and $\mathrm{G} 3$ may be related to the increased tolerance to stretching. Some investigators claim that ROM gains due to a few weeks of stretching might be explained by the increased tolerance to stretching $(3,17)$ rather than a gain in flexibility. Since the muscle presents less resistance to stretching, this might contribute to reducing EMG activity during stretching.

McBride et al. (6) investigated EMG activity during the proprioceptive neuromuscular facilitation stretching method and observed an increase in ROM and EMG activity. However, their results should be considered with caution, since they proposed that passive stretching may be safer than active techniques. Indeed, $88 \%$ of their volunteers reported that passive stretching procedures were more comfortable.

Alternatively, Branco et al. (19) investigated the effects of a 6 -week passive stretching program on the EMG activity of the biceps femoris and did not observe significant differences between the stretching and control groups. The authors concluded that EMG activity during stretching is very low, perhaps due to the relaxation of the neuromuscular system.

Although these hypotheses help conceptualize our findings, studies with larger samples, different stretching techniques and/or longer stretching programs, are needed in order to reconcile the contradictory findings.

Regarding EMG activity during MIC, no significant differences were found after the stretching program. Similarly, Cabral et al. (5) and McBride et al. (6) did not find changes in EMG activity after stretching during MIC. On the other hand, Secchi et al. (18), in a study on the soleus muscle of rats, found that stretching induced muscle hypertrophy, a fact that, theoretically, could improve EMG activity. Accordingly, further studies associating EMG activity with muscle force evaluation in humans are also necessary.

Studies investigating the influence of muscle length on EMG during MIC have reported increased EMG activity when muscles are in a stretched position, and reduced activity when muscles are shortened (20). A hypothesis explaining this could be based on changes in the relationship between length and tension. If stretching really induces myofibrillogenesis $(1,16)$, plastic changes in muscle structure would alter the length-tension relationship. Improved interaction between actomyosin bridges may have led to better muscle recruitment (2), increasing EMG activity.

In conclusion, EMG activity showed no significant difference during $\mathrm{MIC}$ and a trend to reduction during stretching. We suggest that stretching programs performed three times a week yield better gains in flexibility than those performed once a week and similar to those performed five times a week, when the goal is the improvement in flexibility and range of motion. 


\section{References}

1. Bandy WD, Irion JM, Briggler M. The effect of time and frequency of static stretching on flexibility of the hamstring muscles. Phys Ther 1997; 77: 1090-1096.

2. Roberts JM, Wilson K. Effect of stretching duration on active and passive range of motion in the lower extremity. $\mathrm{Br} \mathrm{J}$ Sports Med 1999; 33: 259-263.

3. Halbertsma JP, Goeken LN. Stretching exercises: effect on passive extensibility and stiffness in short hamstrings of healthy subjects. Arch Phys Med Rehabil 1994; 75: 976981.

4. Ferber R, Osternig L, Gravelle D. Effect of PNF stretch techniques on knee flexor muscle EMG activity in older adults. $J$ Electromyogr Kinesiol 2002; 12: 391-397.

5. Cabral CMN, Yumi C, Sacco ICN, Casarotto RA, Marques AP. Eficácia de duas técnicas de alongamento muscular no tratamento da síndrome femoropatelar: um estudo comparativo. Fisioter Pesq 2007; 14: 48-56.

6. McBride JM, Deane R, Nimphius S. Effect of stretching on agonist-antagonist muscle activity and muscle force output during single and multiple joint isometric contractions. Scand J Med Sci Sports 2007; 17: 54-60.

7. Gajdosik R, Lusin G. Hamstring muscle tightness. Reliability of an active-knee-extension test. Phys Ther 1983; 63: 10851090.

8. Santos A. Diagnóstico clínico postural: um guia prático. São Paulo: Summus; 2001.

9. Perret C, Poiraudeau S, Fermanian J, Colau MM, Benhamou MA, Revel M. Validity, reliability, and responsiveness of the fingertip-to-floor test. Arch Phys Med Rehabil 2001; 82: 1566-1570.

10. Sacco IC, Konno GK, Rojas GB, Arnone AC, Passaro AC, Marques AP, et al. Functional and EMG responses to a physical therapy treatment in patellofemoral syndrome patients. J Electromyogr Kinesiol 2006; 16: 167-174.
11. De Luca CJ. The use of surface electromyography in biomechanics. J Appl Biomech 1997; 13: 135-163.

12. de Weijer VC, Gorniak GC, Shamus E. The effect of static stretch and warm-up exercise on hamstring length over the course of 24 hours. J Orthop Sports Phys Ther 2003; 33: 727-733.

13. Ferreira GN, Teixeira-Salmela LF, Guimaraes CQ. Gains in flexibility related to measures of muscular performance: impact of flexibility on muscular performance. Clin J Sport Med 2007; 17: 276-281.

14. De Deyne PG. Application of passive stretch and its implications for muscle fibers. Phys Ther 2001; 81: 819-827.

15. Gajdosik RL. Passive extensibility of skeletal muscle: review of the literature with clinical implications. Clin Biomech 2001; 16: 87-101.

16. Coutinho EL, Gomes AR, Franca CN, Oishi J, Salvini TF. Effect of passive stretching on the immobilized soleus muscle fiber morphology. Braz J Med Biol Res 2004; 37 : 1853-1861.

17. Shrier I, Gossal K. Myths and truths of stretching. Phys Sports Med 2000; 28: 57-63.

18. Secchi KV, Morais CP, Cimatti PF, Tokars E, Gomes ARS. Efeito do alongamento e do exercício contra-resistido no músculo esquelético de rato. Rev Bras Fisioter 2008; 12: 228-234.

19. Branco VR, Negrão Filho RF, Padovani CR, Azevedo FM, Alves N, Carvalho AC. Relação entre a tensão aplicada e a sensação de desconforto nos músculos isquiotibiais durante o alongamento. Rev Bras Fisioter 2006; 10: 465-472.

20. Cresswell AG, Loscher WN, Thorstensson A. Influence of gastrocnemius muscle length on triceps surae torque development and electromyographic activity in man. Exp Brain Res 1995; 105: 283-290. 